\title{
Clarifying assent in pediatric research
}

\author{
Noor AA Giesbertz ${ }^{\star, 1}$, Annelien L Bredenoord ${ }^{1}$ and Johannes JM van Delden ${ }^{1}$
}

\begin{abstract}
Assent is a relatively young term in research ethics, but became an often mentioned ethical requirement in current pediatric research guidelines. Also, the European Society of Human Genetics considers assent an important condition for the inclusion of children in biobanks. However, although many emphasize the importance of assent, few explain how they understand the concept and few have elaborated on the underlying grounds. In this paper, we will discuss the different underlying ethical principles of assent. In the first category, assent appears to be derived from informed consent. This understanding is grounded in respect for autonomy and protection against harm. We conclude that this interpretation of assent is not of added value as a majority of children cannot be considered competent to make autonomous decisions. In addition, other safeguards are more appropriate to protect children against harm. The grounds from the second category can be classified as engagement grounds. These grounds do justice to the specifics of childhood and are of added value. Furthermore, we argue that it follows that both the content and the process of assent should be adjusted to the individual child. This can be referred to as personalized assent. Personalized assent is an appeal to the moral responsibility and integrity of the researcher.
\end{abstract}

European Journal of Human Genetics (2014) 22, 266-269; doi:10.1038/ejhg.2013.119; published online 12 June 2013

Keywords: assent; pediatric research; biobank; ethics

\section{INTRODUCTION}

The inclusion of children in biobank research is considered important for the advancement of pediatric health care. ${ }^{1-5} \mathrm{~A}$ biobank can be defined as a collection of human biological samples stored for medical-scientific research purposes, usually linked to phenotypic data in one way or another. ${ }^{6-8}$ Hence, the primary goal of biobanks is to facilitate research, not to provide medical care. The inclusion of children in biobanks brings forward specific ethical issues. Notably, at the moment of inclusion, children are not able (and legally not allowed) to give consent and they are considered a vulnerable research population. In order to provide children with adequate protection against harm, appropriate safeguard measures are needed.

In current guidelines, assent is an often mentioned ethical requirement for the inclusion of children in biomedical research. ${ }^{9-11}$ Also, the European Society of Human Genetics (ESHG) considers assent an important condition for the inclusion of a child's material in biobanks, as they put forward in a recent policy statement. ${ }^{12}$ With regard to the different types of pediatric biobanks, the prevailing view is that assent should be obtained when possible.,13-19 However, though many emphasize the importance of assent, few explain how they understand the concept and few have elaborated on the underlying grounds of assent and its role in pediatric biobanks. ${ }^{20}$ This is not surprising as no consensus exists about how assent should be interpreted and implemented in biomedical research. ${ }^{21-28}$ The importance of conducting ethically sound pediatric biobank research ${ }^{29}$ and the rapid developments in this field stress the need to scrutinize the concept of assent in pediatric biobank research. ${ }^{14,18}$ Here, we will provide a conceptual analysis of assent, discuss the different underlying ethical principles and its, in our opinion, most tenable interpretation in pediatric research. In addition, we will consider how it should be implemented in biomedical research.

\section{INTERPRETATION OF ASSENT: POTENTIAL UNDERLYING GROUNDS}

Assent is a relatively young term in research ethics. Although it already appeared in a report by the US National Commission for the Protection of Human Subjects of Biomedical and Behavioral Research in $1977,{ }^{27,30}$ it was only introduced in the 5 th version of the Declaration of Helsinki in 2000 (the statement of the World Medical Association of ethical principles for medical research with human participants). ${ }^{9,31}$

In the past years, different underlying grounds for the attainment of assent have been put forward in the literature. They can broadly be divided into two categories. The grounds in the first category appear to be derived from informed consent. Assent is interpreted and used here by analogy of informed consent, as a kind of copy or imitation. By contrast, the second category of grounds allocate assent with a specific task and present it as a concept distinct from informed consent.

\section{Category I--derived from informed consent}

The grounds of the first category are similar to underlying reasons for obtaining informed consent, particularly 'respect for autonomy' and 'protection of the research participant."

Concerning the first ground, 'respect for autonomy', it needs to be taken into account that a person must have the capacity to make autonomous decisions before she is thought of as an autonomous person. Children are deemed to have insufficient decision-making capacities and are therefore, in general, not regarded as autonomous persons. As their cognitive development is incomplete, they are considered to lack an adequate understanding of the research proposal. In addition, they seem more vulnerable to the influences of their surroundings (eg, parents), and the voluntariness of their decisions is at least questionable. ${ }^{33}$ However, typical for children is

${ }^{1}$ Department of Medical Humanities, Julius Center, University Medical Center Utrecht, Utrecht, The Netherlands

*Correspondence: NAA Giesbertz, Department of Medical Humanities, Julius Center, University Medical Center Utrecht, Office Stratenum 6.131, P0 Box 85500, Utrecht, 3508 GA, The Netherlands. Tel: +31 88 7568374; Fax: +31 88 7568099; E-mail: n.giesbertz@umcutrecht.nl

Received 23 January 2013; revised 22 April 2013; accepted 1 May 2013; published online 12 June 2013 
that this incapability is temporary, as their capacity to make autonomous decisions develops as they grow older.

When grounding assent in 'respect for autonomy', assent can only be reserved for those children who are capable of making autonomous decisions about research participation. Children will need to reach a certain threshold before they can be asked to assent. The setting of this threshold is a subject of discussion. It is unclear what a child should understand in order to make an autonomous decision about research participation and also when a child reaches this level. ${ }^{34}$ For instance, it has been suggested that children should be capable of understanding the risks, benefits and the procedure, ${ }^{35}$ or that they should be capable of understanding altruism. ${ }^{36}$

A second ground for assent that has been put forward in the literature is the 'protection rationale. ${ }^{20}$ It is in line with the reasoning behind informed consent and refers to the capacity of a person to protect herself against harm by having control over what happens to her. In research with children, the protective function of informed consent is usually considered to be warranted by the requirement of parental permission, combined with more strict regulations about acceptable risks, the supervision of research ethics committees (REC) and the responsibility of clinicians/researchers. ${ }^{37-39}$ As proxies could misjudge the impact or distress of a study on a child, there remains a role for the child to protect herself as well. However, this role rather takes the shape of 'dissent ${ }^{36,40}$ instead of assent, and is linked to the widely supported view that the dissent (or distress) of a child should always be respected, at least when the research does not offer potential benefits directly to the child.9,39-41 Although respect for dissent is generally accepted, there is a lack of clarity about dissent as well, particularly regarding the question when opposition counts as valid dissent. ${ }^{42}$ It has been argued that not every sign of dissent should be treated this way, but that first the reason behind the dissent needs to be uncovered. ${ }^{36}$ For example, when the objection of the child has nothing to do with distress for the study but she rather wants to play in the playground, this should not be interpreted as dissent. ${ }^{43,44}$ In addition, it is not clear how the silence of a child should be interpreted. Some define dissent as opposition or silence, ${ }^{45}$ while others refer to it as the absence of assent. ${ }^{46}$ We will return to the interpretation of the silence of the child later.

Although in reality instructions for assent are often derived from informed consent, ${ }^{20,26}$ many have objected against grounding assent in the underlying reasons similar to informed consent. ${ }^{20,23,33,39,47-50}$ When one would ground assent in respect for autonomy, it is one of the two: either children are considered incapable of autonomous decision-making and then it does not make sense to use a concept that requires autonomy, or a child can be considered competent to make autonomous decisions and then it would be untenable not to grant the child the same level of control as an adult, at least from an ethical perspective. In that case, the informed consent procedure could be expanded to apply to competent children as well. ${ }^{51}$ Protection against harm, the second ground, seems to be safeguarded mainly in other ways than assent: parental permission, more strict regulations about acceptable risks, the supervision of RECs, the responsibility of clinicians/researchers and respect for dissent. To conclude, assent derived from informed consent does not seem to have a real added value.

\section{Category II--engagement grounds}

Other grounds that have been put forward for assent lead to a more distinct role for assent. The first ground in this category, respect for the child and its developing autonomy, ${ }^{23,24,33,39}$ has also been referred to as the 'development' rationale. ${ }^{20}$ Supporters of this view generally argue that the principle of respect for a person requires that children are empowered to participate in decision-making to the extent of their capacity. As, in general, a child's capacities will develop as it grows older, its role in the decision-making process should increase as well.

A second, closely related, ground is the promotion of or the support for the development of the child. Assent in this way should be understood as a tool or a means to educate. In this case the obtainment of assent contributes to the child's upbringing and moral education. It has been suggested that through assent, different lessons can be passed on during participation in biomedical research, such as fostering autonomy, teaching altruism and supporting selfconfidence. $^{20,30,33,48,50,52}$

The third ground in this category considers assent as a support for communication between the researcher and the child. ${ }^{20}$ An assent requirement most likely incites the researcher to provide research information to the child. ${ }^{52}$ As a result, the child's trust towards the researcher may be promoted, which in turn can lead to a better researcher-child relationship. ${ }^{46}$ This is especially important when the researcher is also the treating physician.

As these grounds from the second category do justice to the specifics of childhood, they are more appealing and have more added value. Assent understood in this way focuses on the involvement or engagement of the child in the decision-making process and has been referred to as the 'development' rationale. ${ }^{20}$

\section{IMPLEMENTATION OF ASSENT: ITS POTENTIAL CONTENT AND PROCESS}

Thus, we concluded that assent should be understood from an engagement point of view. The aim is a child's involvement in the decision-making process. The next step is to determine how assent should be designed in order to reach this goal. Two important elements of assent are the content, that is, which information will be discussed, and the process, that is, how the information will be discussed and which reaction will be considered assent. ${ }^{33,39}$

Concerning the content of assent, there are different levels of information that a researcher can present to a child, ranging from basic information to a content that resembles the information that would be presented to a competent adult. ${ }^{24}$ When the goal is to engage the child in the decision-making process, it follows that the amount of information should be adjusted to the developmental level of the child. It is therefore important to realize that the content of assent should be considered dynamic, not fixed. This may mean that the information provided can range from, for example, the procedure of blood drawing to concepts referring to altruism or returning individual research results. ${ }^{53,54}$ An estimation of the appropriate amount and type of information should be made before the assent procedure takes place, for example, preparing of written information pamphlets for children. However, during the assent procedure it should be assessed whether the information was appropriate for the individual child. It may, for instance, be necessary to explain the information in an easier way to some children, while others would like to have extra information. ${ }^{55}$

In the process of the obtainment of assent, the manner of information disclosure and the reaction of the child are of great importance. First, it has been the subject of discussion whether research information should be communicated in written and/or verbally. ${ }^{35}$ As disclosing information in both ways increases understanding of the child, ${ }^{35}$ it is preferable to use both methods in such a way that they supplement each other. ${ }^{56}$ Obviously, this should also be adjusted to the child and written information should 
only be provided when the child is able to read. In addition, other techniques can be used as well, for example, pictures to clarify the verbal information, but additional studies should be performed to optimize understanding. ${ }^{57}$

Second, it is important to decide which reaction of the child is sufficient for assent. Two themes of importance here are, the interpretation of silence and whether or not a signature is required. As discussed, it is unclear how silence should be interpreted. When we address this question in the light of assent founded in engagement grounds, it seems convincing that silence should not be considered sufficient for assent, except when it is paired with a non-verbal reaction such as nodding. When the goal is to truly engage children, it would be inconsistent to treat 'no-reaction' as assent. Second, the requirement of a signature has been the subject of discussion. It has been recommended that a signature should be obtained when the child is able to provide it. ${ }^{41}$ No clear motivation was provided by the authors so we can only speculate, but this requirement could have been set in order to motivate the researcher to include the child in the decision-making process or because it is a clear and explicit requisite. However, it is also stated that a signature should not be the focus of an assent procedure. ${ }^{24} \mathrm{~A}$ requirement for a signature could make the assent procedure more rigid and could disturb the relational aspect. ${ }^{46}$ In addition, when a signature would be a requisite, there is a risk of focusing too much on merely the signature as it can be a form to protect the researcher against legal claims. Therefore, we think a signature should not be a strict requirement for assent procedures.

\section{IMPLICATION: PERSONALIZED ASSENT}

Both elements, the content and the process of assent, need to be adjusted according to the child's capabilities and the study at hand in order to accomplish optimal engagement. This implies that there is no 'one-size-fits-all' assent procedure for all children in research. ${ }^{34}$ Different elements should therefore be assessed in order to determine the child's capacity to assent. When the development of children is considered to evolve in stages, ${ }^{58}$ age can easily be used to categorize children into groups, as is also the case at the moment. Assent can be adjusted in accordance to the expected development, for example, to offer information for the different age categories. Although this approach has a practical advantage, it can be criticized as well. Linking a child's capacity solely to age would not do justice to the individual differences between (the development of) children. ${ }^{39}$ Factors such as individual circumstances, life experiences, emotional and psychological maturity, intellectual capabilities and the child's family have all been put forward as elements that should be taken into account in the assent procedure. ${ }^{15,25,33,45,47,59,60}$ We therefore arrive at a more individualized or case-by-case approach. ${ }^{15,55,59}$ This can be referred to as personalized assent. A similar line of reasoning can be found in the Gillick competency judgment, insofar as they both assess the maturity and competency of the child. The concept of the Gillickcompetent child refers to a child below the age of 16 who is considered mature enough to be legally allowed to give consent to a clinical procedure. ${ }^{61}$ It has been proposed that the concept of Gillick competency can be applied to pediatric research as well. ${ }^{62}$

For personalized assent an (inter)active structure of assent is required - the content and the process needs to be adjustable to the individual child and assent should be thought of as an ongoing process instead of a single act. In addition, personalized assent possibly effects the issues of recontact and reconsent. However, the exact implications are complex and beyond the scope of this paper.
The requirement of a personalized assent gives rise to a dilemma. As the potential level of engagement will be different in each case, fixed end-points are difficult to determine. Instead, accepting a child's right to personalized assent implies a researcher's duty to commit herself to involve a child in the decision-making process as much as possible. We are aware that the demandingness of this duty is difficult to determine. It raises the question which efforts are reasonable to expect from researchers to engage a child in the decision-making process. As the assent procedure should be adjusted to the child's capabilities and the study at hand, it is difficult to formulate a general answer to this question. It would be more appropriate to address this issue by discussing specific research areas and cases.

\section{CONCLUSION}

Although many consider assent an important ethical requirement for the inclusion of children in biobanks, as is recently shown by the ESHG, few explain how they define and interpret assent. In this paper, it is argued that assent should be understood from engagement grounds in order to do justice to the characteristics of childhood. It follows that both the content and the process of assent should be adjusted to the individual child and study, which can be referred to as personalized assent. Although fixed end-points are appealing from a practical perspective, it is difficult to provide these with assent interpreted from an engagement point of view. Further discussion is needed to provide a concrete filling in of the duty to seek personalized assent in pediatric biobanking. Nevertheless, at this point, we make an old-fashioned appeal to the moral integrity and responsibility of the researcher with this contemporary interpretation of assent.

\section{CONFLICT OF INTEREST}

The authors declare no conflict of interest.

\section{ACKNOWLEDGEMENTS}

The authors acknowledge funding from ZonMw - The Netherlands Organization for Health Research and Development.

1 Salvaterra E, Giorda R, Bassi MT et al: Pediatric biobanking: a pilot qualitative survey of practices, rules, and researcher opinions in ten European countries. Biopreserv Biobank 2012; 10: 29-36.

2 Gilheeney SW, Kieran MW: Differences in molecular genetics between pediatric and adult malignant astrocytomas: age matters. Future Oncol 2012; 8: 549-558.

3 Merlo DF, Knudsen LE, Matusiewicz K, Niebroj L, Vahakangas KH: Ethics in studies on children and environmental health. J Med Ethics 2007; 33: 408-413.

4 Pedersen M, Merlo DF, Knudsen LE: Ethical issues related to biomonitoring studies on children. Int J Hyg Environ Health 2007; 210: 479-482.

5 Van Larebeke NA, Birnbaum LS, Boogaerts MA et al: Unrecognized or potential risk factors for childhood cancer. Int J Occup Environ Health 2005; 11: 199-201.

6 Organisation for Economic Co-Operation and Development: OECD Guidelines on Human Biobanks and Genetic Research Databases. OECD: Paris, 2009.

7 Council of Europe, Committee of Ministers: Recommendation Rec (2006) 4 of the Committee of ministers to member states on research on biological materials of human origin. Council of Europe 2006

8 Giesbertz NAA, Bredenoord AL, van Delden JJM: Inclusion of residual tissue in biobanks: opt-in or opt-out? PLoS Biol 2012; 10: e1001373.

9 World Medical Association: WMA Declaration of Helsinki-Ethical Principles for Medical Research Involving Human Subjects. WMA: Seoul, 2008.

10 Council for International Organizations of medical Sciences (CIOMS): Internationa Ethical Guidelines for Biomedical Research Involving Human Subjects. CIOMS Geneva, 2002.

11 U.S. Department of Health and Human Services: Human Subjects Research (45 CFR 46, Subpart D). Protections for Children Involved as Subjects in Research 2009.

12 Hens K, Van EI CE, Borry $\mathrm{P}$ et al: Developing a policy for paediatric biobanks: principles for good practice. Eur J Hum Genet 2013; 21: 2-7.

13 Hens K, Nys H, Cassiman JJ, Dierickx K: Biological sample collections from minors for genetic research: a systematic review of guidelines and position papers. Eur J Hum Genet 2009; 17: 979-990. 
14 Ries NM, LeGrandeur J, Caulfield T: Handling ethical, legal and social issues in birth cohort studies involving genetic research: responses from studies in six countries. BMC Med Ethics 2010; 11: 4

15 Samuël J, Ries NM, Malkin D, Knoppers BM: Biobanks and longitudinal studies: where are the children? GenEdit 2008; 6: 1-8.

16 Kaufman D, Geller G, LeRoy L, Murphy J, Scott J, Hudson K: Ethical implications of including children in a large biobank for genetic-epidemiologic research: a qualitative study of public opinion. Am J Med Genet C 2008; 148C: 31-39.

17 Patenaude AF, Senecal K, Avard D: Whither paediatric research and predisposition genetic testing? GenEdit 2006; 4: 1-9.

18 Ries NM: Growing up as a research subject: ethical and legal issues in birth cohort studies involving genetic research. Health Law J 2007; 15: 1-41.

19 Knoppers BM, Avard D, Cardinal G, Glass KC: Science and society: children and incompetent adults in genetic research: consent and safeguards. Nat Rev Genet 2002; 3: 221-225.

20 Wilfond BS, Diekema DS: Engaging children in genomics research: decoding the meaning of assent in research. Genet Med 2012; 14: 437-443.

21 Baines P: Assent for children's participation in research is incoherent and wrong. Arch Dis Child 2011; 96: 960-962.

22 Wilkinson D: Dissent about assent in paediatric research. J Med Ethics 2012; 38: 2.

23 Sibley A, Sheehan M, Pollard AJ: Assent is not consent. J Med Ethics 2012; 38: 3.

24 Kon AA: Assent in pediatric research. Pediatrics 2006; 117: 1806-1810.

25 Gibson BE, Stasiulis E, Gutfreund S, McDonald M, Dade L: Assessment of children's capacity to consent for research: a descriptive qualitative study of researchers' practices. J Med Ethics 2011; 37: 504-509.

26 Whittle A, Shah S, Wilfond B, Gensler G, Wendler D: Institutional review board practices regarding assent in pediatric research. Pediatrics 2004; 113: 1747-1752.

27 Unguru Y, Coppes MJ, Kamani N: Rethinking pediatric assent: from requirement to ideal. Pediatr Clin North Am 2008; 55: 211-222.

28 Kimberly MB, Hoehn KS, Feudtner C, Nelson RM, Schreiner M: Variation in standards of research compensation and child assent practices: a comparison of 69 institutional review board-approved informed permission and assent forms for 3 multicenter pediatric clinical trials. Pediatrics 2006; 117: 1706-1711.

29 Samuel J, Knoppers BM, Avard D: Paediatric biobanks: what makes them so unique? J Paediatr Child Health 2011; 48: E1-E3.

30 The National Commission for the Protection of Human Subjects of Biomedical and Behavioral Research: Research Involving Children: Report and Recommendations, DHEW Pub. No. (OS) 77-0004GPO: Washington, 1977.

31 Carlson RV, Boyd KM, Webb DJ: The revision of the declaration of Helsinki: past, present and future. Br J Clin Pharmacol 2004; 57: 695-713.

32 Beauchamp TL, Childress JF: Principles of Biomedical Ethics, 6th edn, New York/ Oxford: Oxford University Press, 2009; 118.

33 Miller VA, Nelson RM: A developmental approach to child assent for nontherapeutic research. J Pediatr 2006; 149: S25-S30.

34 Ashcroft R, Goodenough T, Williamson E, Kent J: Children's consent to research participation: social context and personal experience invalidate fixed cutoff rules. $A m \mathrm{~J}$ Bioeth 2003; 3: 16-18.

35 Tait AR, Voepel-Lewis T, Malviya S: Do they understand? (part II): assent of children participating in clinical anesthesia and surgery research. Anesthesiology 2003; 98: 609-614.

36 Wendler D, Shah S: Should children decide whether they are enrolled in nonbeneficial research? Am J Bioeth 2003; 3: 1-7.

37 Denham EJ, Nelson RM: Self-determination is not an appropriate model for understanding parental permission and child assent. Anesth Analg 2002; 94: 1049-1051.
38 Kodish E: Informed consent for pediatric research: is it really possible? J Pediatr 2003; 142: 89-90.

39 Rossi WC, Reynolds W, Nelson RM: Child assent and parental permission in pediatric research. Theor Med Bioeth 2003; 24: 131-148.

40 Wendler DS: Assent in paediatric research: theoretical and practical considerations. J Med Ethics 2006; 32: 229-234.

41 European Commission. Ethical Considerations for Clincial Trials on Medicinal Products Conducted with the Paediatric Population: Recommendations of the Ad Hoc Group for the Development of Implementing Guidelines for Directive 2001/20/EC Relating to Good Clinical Practice in the Conduct of Clinical Trials on Medicinal Products for Human UseEuropean Commission: Brussels, 2008.

42 Botkin JR: Preventing exploitation in pediatric research. Am J Bioeth 2003; 3: 31-32.

43 Joffe S: Rethink 'affirmative agreement,' but abandon 'assent'. Am J Bioeth 2003; 3: 9-11.

44 Moeller CJ: Moral responsiveness in pediatric research ethics. Am J Bioeth 2003; 3: W1-W3.

45 Solyom AE: Omitted considerations and populations: a response to 'should children decide whether they are enrolled in nonbeneficial research?' by David Wendler and Seema Shah (AJOB 3:4). Am J Bioeth 2004; 4: W39-W40.

46 American Academy of Pediatrics: Committee on Bioethics. Kohrman A, Wright Clayton $\mathrm{E}$, Frader JE et al: Informed consent, parental permission, and assent in pediatric practice. Pediatrics 1995; 95: 314-317.

47 Nelson RM, Reynolds WW: We should reject passive resignation in favor of requiring the assent of younger children for participation in nonbeneficial research. Am J Bioeth 2003; 3: 11-13.

48 Diekema DS: Taking children seriously: what's so important about assent? Am J Bioeth 2003; 3: 25-26.

49 Bartholome WG: A new understanding of consent in pediatric practice: consent, parental permission, and child assent. Pediatr Ann 1989; 18: 262-265.

50 Bartholome WG: In defense of a child's right to assent. Hastings Cent Rep 1982; 12 : 44-45.

51 Baylis F, Downie J: The limits of altruism and arbitrary age limits. Am J Bioeth 2003; 3: 19-21.

52 Leikin S: Minors' assent, consent, or dissent to medical research. IRB 1993; 15: 1-7.

53 Avard D, Senecal K, Madadi P, Sinnett D: Pediatric research and the return of individual research results. J Law Med Ethics 2011; 39: 593-604.

54 Bredenoord AL, de Vries MC, van Delden JJM: Next-generation sequencing: does the next generation still have a right to an open future? Nat Rev Genet 2013; 14: 306.

55 Erb TO, Schulman SR, Sugarman J: Permission and assent for clinical research in pediatric anesthesia. Anesth Analg 2002; 94: 1155-1160.

56 Ungar D, Joffe S, Kodish E: Children are not small adults: documentation of assent for research involving children. J Pediatr 2006; 149: S31-S33.

57 Adcock KG, Hogan SM, Elci OU, Mills KL: Do illustrations improve children's comprehension of assent documents? J Pediatr Pharmacol Ther 2012; 17: 228-235.

58 Piaget J: The Origins of Intelligence in Children, 5th edn International Universities Press, Inc: New York, 1969.

59 Fernandez CV: Context in shaping the ability of a child to assent to research. Am J Bioeth 2003; 3: 29-30.

60 Frader JE: We need substantive criteria for decisions by children. Am J Bioeth 2003; 3: 8-9.

61 Larcher V, Hutchinson A: How should paediatricians assess Gillick competence? Arch Dis Child 2010; 95: 307-311.

62 Hunter D, Pierscionek BK: Children, Gillick competency and consent for involvement in research. J Med Ethics 2007; 33: 659-662. 